\title{
Gross domestic product growth, volatility and regime changes nexus: the case of Portugal
}

\author{
Jorge M. Andraz ${ }^{1,2,3}$ \& Nélia M. Norte ${ }^{1,2}$
}

Received: 5 April 2015 / Accepted: 26 January 2017 /Published online: 8 February 2017

\# ISEG 2017

\begin{abstract}
This paper provides evidence of the behavior of GDP growth volatility in Portugal over the period from 1961 to 2016 with the main objective of measuring the degree of asymmetry of GDP growth rates volatility across the business cycles and its persistence over time. The methodological setting benefits from the most recent developments that recommend the consideration of structural changes in both the mean and variance and asymmetric reactions of volatility to positive and negative shocks. The results document structural changes and significant reductions of GDP growth rates volatility consistent with the "Great Moderation" phenomenon and reveal that the impact of negative shocks on volatility exceeds that of positive shocks more than 4 times over the sample period. Moreover, these asymmetries follow a rather stable pattern over the sample period, suggesting that the Portuguese economy has not been able to reduce its growth vulnerability to cyclical fluctuations.
\end{abstract}

Keywords GDP. Volatility $\cdot$ Structural change $\cdot$ GARCH $\cdot$ Portugal

JEL Classification $\mathrm{C} 22 \cdot \mathrm{E} 23 \cdot \mathrm{E} 32$

Jorge M. Andraz

jandraz@ualg.pt

Nélia M. Norte

nnorte@ualg.pt

1 Faculdade de Economia, Universidade do Algarve, Campus de Gambelas, Edifício 9, 8005-139 Faro, Portugal

2 CEFAGE-UE- Center for Advanced Studies in Management and Economics, Universidade de Évora, Évora, Portugal

3 Faculty of Economics, University of Algarve, Campus de Gambelas, Edifício 9, 8005-496 Faro, Portugal 